\title{
Challenges of Communicating Cervical Cancer Screening Awareness and Uptake in Bungoma County, Kenya
}

\author{
FAITH KISIANGANI, Daystar University (Lead author)
}

REGINAH GACHARI, PhD. Daystar University

LEAH JEROP KOMEN, PhD., Daystar University

\begin{abstract}
There have been ongoing cervical cancer campaigns in Kenya, targeting cervical cancer awareness and the need to go for cervical cancer screening (National Cervical Cancer Prevention Program, 2012). However, data depicts that there is a low level of screening and uptake among the rural population (ICO Information Centre on HPV and Cancer, 2014). This study adopted a descriptive research design, taking on qualitative data methods of focus groups discussions and in depth interviews, with a purpose of finding out the communication challenges of cervical cancer screening awareness and uptake among rural women in Bungoma County, Kenya. The objectives of the study were to: find out the communication channels used during the campaigns; and to understand the challenges of communicating cervical cancer screening messages to rural women in Bungoma County. A total of 40 women were interviewed from the Mt. Elgon Constituency in Bungoman County. The data was analysed by using QSR-Nvivo. The findings of the research showed that the main communication channels of cervical cancer were media, health education, and road shows. The main communication challenges of cervical cancer screening and uptake were: lack of cervical cancer terminology; inadequate information on the communication channels; and fear among women. There were low levels of cervical cancer awareness and uptake among the participants. One of the recommendations was the need for educating media personalities and other key health informants on cervical cancer for increase in uptake of screening services.
\end{abstract}

\section{KEYWORDS}

Cervical cancer, Cervical cancer screening, Human Papillomavirus (HPV), Communication, Communication channels, key health informants

\section{Introduction / Background}

Cervical cancer accounts for 275,000 deaths globally every year, out of which at least $87 \%$ deaths occur in developing countries (World Health Organization 2014). Sibiya (2012) observed that most deaths caused by cervical cancer in developing countries, especially in the 
Sub-Saharan Africa, are as a result of lack of screening that permits precancerous detection and prevention at an early stage. The lack of early cervical cancer screening is usually as a result of low levels of knowledge and awareness on the disease (Nyambane, Mberia, and Ndati 2015).

Although the media is considered as the most reliable source of communicating cervical cancer information, research shows that there are still some communication challenges during the process of disseminating information through the media (Parhizkar et al. 2012). During the communication process of cervical cancer, for instance, various challenges may arise such as, low levels of awareness, myths and misconceptions, fear, stigma, and language barriers (Kutto 2014).

In Kenya, almost 2,451 out of 4,802 women diagnosed with cervical cancer die annually (WHO 2014). The percentage of women who attend cervical cancer screening from the rural areas in the country is lower compared to those in the urban areas (ICO Information Centre on HPV and Cancer 2014). Several communication platforms have therefore been adopted for cervical cancer screening awareness in the country (Nyambane et al. 2015). However, research depicts that the cervical cancer awareness level is still low among the general population in the country despite the on-going awareness and campaigns programmes (Gichangi et al. 2003; Nyambane et al. 2015).

There is a low level of cervical cancer screening among the rural population as compared to the urban population. Data depicts that $2.6 \%$ of women from the rural areas in Kenya are screened for cervical cancer compared to $4.0 \%$ of urban women after every 3 years (ICO Information Centre on HPV and Cancer 2014). This study therefore sought to establish the communication challenges during cervical cancer screening awareness and uptake among rural women.

\section{The research question}

This research sought to find out what challenges exist in using communication health campaigns to promote the awareness and uptake of cervical screening among rural women in Kenya with specific focus on the women of Bungoma County.

\section{Research objectives}

This research was guided by the following three research objectives: -

1. To map out communication channels used for cervical cancer campaigns that rural women (18-50 years of age) in Bungoma County were exposed to

2. To establish the communication challenges that women in rural areas (18-50 years of age) face with regard to cervical cancer screening health campaigns

3. To critically examine the levels of awareness of cervical cancer among rural women (1850 years of age) in Bungoma County 


\section{Theoretical framework: Theory of reasoned action and health belief mode}

The Theory of Reasoned Action (TRA) suggests that the strength of a person's intention to perform certain behaviour determines his/her behavioural performance (Ajzen \& Fishbein, 1980). There are two kinds of beliefs under this theory: the normative beliefs; and the behavioural beliefs. The normative beliefs influence subjective norms and occur when an individual places other people's approval on the behaviour he wishes to perform (Schiavo, 2007) and his motivation to comply with the approvals and ideas from them. The behavioural belief, on the other hand, is the attitude of an individual towards certain behaviour on the consequences of performing such behaviour. Communication is crucial in the theory of reasoned action because it aids in the process of supporting behavioural intentions and changing subjective norms, and therefore, increasing its likelihood to become the actual behaviours on the targeted individuals (Schiavo, 2007). Women who have obtained relevant and adequate communication on the importance on cervical cancer screening may change their attitude and practice to curb their susceptibility to the disease.

Schiavo (2007) also argued that this theory is useful during the process of analysing and identifying the messages and actions which need to be adopted to change the targeted group attitudes because it is a good tool in profiling primary and secondary audiences. When communicating cervical cancer screening, there is a need for messages to be tailored to the baseline knowledge, perceptions, culture, and attitudes unique to the target population so that it can change their behavioural perception towards the disease.

The Health belief model HBM suggests that the likelihood of a person to engage in a specific health behaviour is a function of several beliefs: the extent to which one believes that they are susceptible to a particular illness; ones' perception of the severity of the illness' consequences; perceived barriers/costs of adopting a health behaviour; and the perceived benefits of adopting the targeted health behaviour. According to Schiavo (2007), the major contribution of HBM to health communication is its emphasis on the importance of knowledge as a necessary step to change. The knowledge about cervical cancer screening is a strong determinant of screening behaviour (Eggleston, Coker, Das, Cordray, and Luchok 2007). Perceived susceptibility, perceived severity, perceived benefits, perceived barriers and cues to action, all rely on the level of awareness and knowledge about cervical cancer. For example, if a woman has adequate knowledge on cervical cancer, she will be able to know the severity of the disease, the barriers, the benefits of carrying out cervical cancer screening and the susceptibility of the disease. Knowledge is brought to target audiences through an educational approach that primarily focuses on messages, communication channels and spokespeople (Schiavo 2007).

\section{Methodology}

This research was descriptive in nature. Six focus group discussions and three in-depth interviews were conducted based on the research question and objectives of the study. The target population for the study included women in Bungoma County who were aged between 
18 to 50 years because they are at risk of contracting cervical cancer (Eggert 2012). The total number of women involved in the focus group discussions (FGDs) were 40. The health nurse and other community key health informants were also targeted because they are the main source of health information to the community members (National Cervical Cancer Prevention Program 2012).

\section{Sampling procedure}

The researcher carried out the research in Mt. Elgon Constituency of Bungoma County using purposive sampling selection because there were various health reproductive programmes being carried out in the area, including cervical cancer screening programmes (AMPATH Research Program Office 2013; Fleischman 2011; Kenya National Commission on Human Rights 2012; \& UNFPA Kenya Annual Report 2013). Two wards from Mt. Elgon Constituency were targeted because they had cervical cancer screening facilities. The two sub-locations selected were Elgon and Kaptama Wards.

A sample size of 40 women participated in the FGDs and an additional three key health informants of the community participated in the in-depth interviews. The women were identified by using convenient sampling to represent the whole population, based on the ease of access as explained by Kothari (2004). The inclusive criteria were the women who had visited the mother child clinic department of the Mt. Elgon hospital. Participants from a women's group in the community also participated in the FGDs in order to reach the targeted population. The selected health key informants interviewed were engaged in communicating messages on cervical cancer as a health issue to the community members and they included the district public health nurse and community health worker. The community radio journalist was also interviewed as a major key informant in the community.

The participants in FGDs were only women between the ages of 18 to 50 years, and were residents of the selected study population because they were at risk of being infected by cervical cancer. The focus group discussions were therefore drawn from anyone who fitted within the age bracket deemed to be sexually active and prone to cervical cancer but also residents of Bungoma County. The overall number of FDGs conducted was 6 , with at least two groups conducted daily and each taking approximately 40 minutes. Richie and Lewis (2003) stated that a focus group discussion needs to have around 6 to 8 participants so that all the participants will have a chance to participate in the discussions. Richie and Lewis (2003) further noted that the optimum size of the group depends on a number of things, including the complexity and sensitivity of an issue. An issue that is complex and sensitive is better tackled in smaller groups. The researcher therefore carried out focus group discussions involving 6 to 7 participants in each group. The groups were facilitated by the researcher.

The interviews and focus group questions were constructed in English, and were then translated to Kiswahili to break the language barrier during the interview sessions. The researcher used audio to record what the participants were discussing for easy analysis of data because according to Bryman and Bell (2011), focus group discussions need to be recorded 
and transcribed. The researcher used QSR Nvivo for the data analysis. QSR Nvivo is mainly used in qualitative analysis. The themes were derived from the codes and nodes from the QSR-Nvivo programme.

\section{Data collection methods}

Data was collected using focus group discussions and in depth interviews. The questions for the FGDs dealt with the aspects of: whether or not the participants knew of the cervical campaigns; where they got the information from; what conversations ensued with their spouses, for those married, about the need to go for cervical cancer screening; and any challenges they might have or still did experience in making decisions to go for cervical cancer screening. Other questions dwelled on their choice of channels for communication of cervical cancer screening and what cultural beliefs supported or challenged the need to go for cervical cancer screening.

\section{Research findings, analysis and interpretations}

\section{Awareness level of cervical cancer}

In order to understand why women either go or don't go for cervical cancer screening, it was necessary to understand their basic knowledge about cervical cancer disease. Information from the focus group discussions indicated that the participants had low levels of knowledge of the disease and or screening uptake among them.

When the respondents were asked whether they had heard of cervical cancer screening, only 17 out of the 40 participants admitted to have heard of it. The few that heard only heard that it was a serious disease affecting women. This was in agreement with one of the tenets of health belief model, which states that unless one perceives that they are susceptible they may not seek help.

Most of the participants, especially those who claimed they had heard from the radio, said it did not concern them so much as they associated cervical cancer with promiscuous life and other misconceptions. For instance, some believed that the disease was transmitted from a combination of sexually transmitted viruses, being unhygienic, using strong or perfumed bathing soaps and sprays, sharing inner clothing, using condoms, or being intimate with an individual who is suffering from gonorrhoea.

Question: How is cervical cancer transmitted?

G2 R2: Mtu anapata hizi virusi zikiwa combined. Yaani syphilis, gonorrhea na uchafu pia

(A person gets it when the viruses are combined. That is syphilis, gonorrhea and also from dirt). For those who they think they have been faithful, they would not see themselves as capable in the least of having cervical cancer. They totally have no cues to action as it is stipulated in the HBM, and because they do not see themselves at risk, they will not need to change behaviour at all. 
G6 R1: Inapatikana ukihave sexual intercourse with a lot of different men. Chenye inacourse tena ni kutumia hizi vitu kama sprays, sabuni mbaya mbaya na pia ukishare for example panties

(The disease is transmitted when you have sexual intercourse with different men. It is also caused from things like sprays, soaps that are bad and also sharing panties). Again in this respondents' mind, it is not only one cause but convergence of several things, such as, soaps, sprays, and multiple partners, and if they do not see themselves as using any of these, then they do not see the urgency or even the need for screening.

There were participants who admitted to having heard of cervical cancer disease but they did not understand how it was transmitted. One of the participants heard of it and was tested, but she did not fully understand what she was being tested for. There are participants who mentioned that cervical cancer is a disease that affects the uterus and/or the breasts. In such instances, yes they heard over the radio, but they did not understand. It is therefore difficult to change behaviour based on a linear approach to matters of health. The participants could not tell for sure what it is that they heard except the term, cervical cancer, which again, was strange as some would admit.

Question. What does cervical cancer mean to you?

G4 R1: Tulikuwa tunajua vile inaitwa, hatujui ni nini exactly

(We only knew what it is called; we don't know what it is exactly).

G4 R2: Hatujapimwa, hata hatujui ni nini. Hatujui ni nini lakini tunajua venye inaitwa, na hiyo sasa inakujaje?

(We were never tested; even we don't know what it is. We do not know what it is but we know what it is called. How does that come about cervical cancer)?

G4 R3: Mi nishawai pimwa alafu nikaambiwa tuи sina. Niliambiwa tuи ni cancer, wakasema tuu ni cancer, cervical cancer. Lakini hatujaelezwa kabisa ni kitu gani inacause.

(I have been screened and I was just told that I am not infected. I was only told it is cancer, they only say it is cancer, cervical cancer. But we have not been told clearly how it is caused).

G5 R1: Nilisikia tuu ni ile ugonjwa inashika kina mama kwa nini ya uzazi

(I have only heard that it is that disease that affects mothers in that place of the uterus)

G5 R2: Wengine wanasema ni kwa matiti

(Other people say it is on the breast).

These accounts indicate how most of the respondents did not know how cervical cancer comes about, what its symptoms, and what they should look out for. It also shows how cervical cancer is confused for breast cancer as G5 $\mathrm{R} 2$ confesses.

A number of the participants had never undergone cervical cancer screening. From the 40 participants, only 6 had been screened. However, a few participants had inaccurate knowledge of the disease because they incorrectly mentioned that cervical cancer is a sexually transmitted disease, saying it affects a woman's reproductive organ and that some of 
the signs and symptoms include blood, puss discharge, and pains when walking or having sexual intercourse, wounds and itchiness. They were also misinformed of how the disease can be prevented.

\author{
G1 R1: Huwa inadhuru cervix \\ (It affects the cervix). \\ G1R2: Ile ugonjwa inadhuru cervix alafu inafanya mtu anatoa uzaa \\ (It is a disease that affects the cervix and leads to secretion of puss). \\ Question: What are the signs and symptoms of cervical cancer? \\ G2 R1: Mtu akiover bleed, uchungu katikati ya sex \\ (When a person bleeds too much and feels pain during sex). \\ G1 R1: Saa zingine damu inatoka \\ (Sometimes it causes bleeding). \\ G1 R2: Ingine ni kua saa zingine ka unakojoa unasikia uchungu, kutembea ni \\ shida \\ (Another one is sometimes you feel pain when urinating, even walking is a \\ problem). \\ G6 R1: Nilikuwa naskia ati saa zingine ukitouch around that area unaskia \\ kitu kako lump na nipainful \\ (I heard that if you touch around the area you feel something like a lump \\ which is painful). This is also another piece of inaccurate information. No \\ lumps are felt for cervical cancer yet the respondents associated it with lumps \\ too. \\ Question: Can cervical cancer be prevented? \\ G1 R1: Unaeza zuia kwa kupata matibabu na kuwa faithful kwa mtu mmoja \\ (You can prevent it by getting treatment and being faithful to one partner).
}

\title{
2. Cervical cancer communication channels
}

The findings of the study showed that communication channels play a role in promoting cervical cancer screening. There were respondents who had been screened because there were road-shows in the community communicating about free cervical cancer screening in the hospital. One participant was however screened since she had reproductive health complications.

Question: Have you ever been involved in cervical cancer screening? How often? What triggered you to perform it?

G4 R1: Walitangaza Kapsokwony wakasema wamama wakuje kupima. Madaktari. Alafu wakapea nurse mmoja ndo alikuwa anafanya hiyo kazi, na tukapimwa...

(They advertised in Kapsokwon and they said women should get screened by the doctors. They gave one nurse the responsibility of doing that job, and we were screened).

G5 R2: Ata mimi nilipimwa last year wakiannounce twende tupimwe.

(I was also screened during that time that they were making announcements in the community about free cervical cancer screening services). 
Respondents who had been screened and those who had heard of cervical cancer screening admitted that the district hospital advertised about screening services of the disease during the cancer week. The district public health nurse stated that there was an increase in the number of women performing cervical cancer screening during October, usually dubbed the cancer commemoration month as cancer campaigns and many screening are done during this particular month as compared to other times. Other respondents who had never been screened but had knowledge of cervical cancer also mentioned the media as the other source of information on cervical cancer.

Question: Are there any communication channels (media, community health workers, health informants like doctors and nurses, health organizations etc.) that address cancer related issues or sexually transmitted disease in the region? G1 R1: Kuna wakati kulikuwa na matangazo lakini sikujua ni nini. Ilikuwa kwa radio, radio jambo.

(I heard it from radio Jambo although I never understood what the disease was).

G1 R2: Niliwatch kwa Citizen TV alafu nikaskia kwa Mulembe FM

(I watched it on Citizen TV and also heard about it from Mulembe FM).

G2 R1: Niliskia kwa redio, tv na pia kwa mahospitali huwa wanatangaza. Pia waliweka notice

(I heard it from the radio, TV and also the hospital. They had notices).

G6 R1: College, kwa TV, internet, citizen TV, walikuwa wanaongelea causes, risk factors na vile wanataste cervical cancer

(College, citizen television, internet. They were discussing the risk factors, causes and how they test for cervical cancer).

From the responses, it is clear that most communication happen through the mass media such as radio and TV, and also posters, however, it appears not much was gained as participants only remember hearing about it, but not understanding. And of course this is the challenge of linear model or mass media communication that assume a passive audience. The hospital communication seemed to have yielded some level of understanding, as some mentioned having been informed further on how cervical cancer happens.

\section{The communication challenges of cervical cancer screening and uptake}

A number of respondents had heard of cervical cancer but had never been screened. When asked for the reason why they were never screened, they mentioned various factors such as inadequate information from the media or the hospital, fear of being stigmatized, fear of cervical cancer procedure during screening, financial constraints, lack of interest, and lack of enough medical personnel.

\section{Inadequate information from the communication channels}

The majority of the participants who had heard about cervical cancer but had never attended screening services stated that it was because of the inadequate information during the communication process. 
Question 2: Has there been any discussion on the media encouraging women to go for cervical cancer screening? If yes, did the message convince them to go for cervical cancer screening?

G1 R1: 'Hawakukuwa wanaexplain in details cervical cancer ni nini. (They were not explaining in details what cervical cancer is).

G4 R1: Tunaskianga tuu kwa redio lakini hatuambiwi pahali pa kuenda. Lakini hospitali ukiskia wanatangaza wanapita hata kwa njia wakisema wamama mkuje kwa screening ya cancer. Mtu ataamua aaende au asiende.

(We only hear about the disease from the radio but we are not told where to go. But when you hear it advertised from the hospital, they pass on the road saying women you should come for screening. A person will decide to go or not to go).

Some respondents even feared the possible consequences imagining people knowing they went for the cervical cancer screening and had to expose their private parts to some strange doctors, may be even male doctors. They feared being labelled as 'that woman who goes to expose her private parts to male doctors'. This fear of stigmatization and isolation kept some from not going for the screening even if they knew they fell in the category of most probability.

\section{Lack of interest}

There are other respondents who stated that they did not go for cervical cancer screening because they had no interest and were occupied with work when the screening was taking place.

G6 R1: Nilikuwa na interest ya kuenda kujipima after niskie kutoka kwa citizen. Sikuwahi pata nafasi

(I had the interest to go and be screened after I heard from Citizen TV but I never got the time).

G2 R1: Nilikuwa committed

(I was committed).

G2 R2: Sikuwa na haja kwa sababu sijawai kuona anayeugua

(I wasn't interested because I have never seen anyone suffering from it).

Health belief model singles out the susceptibility of severity as some of the determinants for changing behaviour. It is clear from the accounts above that the women who have never seen anyone suffer from cervical cancer did not have someone or something to relate to and so they did not see themselves as at risk even though they were sexually active and within the age bracket of 18-50 years.

\section{Fear}

The respondents also highlighted fear of having the disease as a reason of not performing cervical cancer screening, even after hearing about it. Fear of being judged by the community members and of getting the disease were other factors influencing their decision. 
G5 R1: Tuliogopa kwa sababu walikuwa wanatutisha kuwa ukieza patikana nayo utakuwa na stress. Kwa hivo niliogopa naeza kuwa nayo.

(We feared because they used to make us think that if you are found with it you will be stressed. I thus feared that I may have it).

G4 R2: Lakini pia kila wakati wakikuja, wanatishanga watu. Hata sisi tuliwai fanyiwa ya matiti. Unaenda hapo unapata wamekaa, unafanyiwa ya matiti. Hata mimi niliskia kitu hapa (pointing at one of her breast) nikaanza kuita, daktari kuna kitu, ona iko hapa. Alafu wakaita daktari wengine. Wakaangalia wakapata hakuna kitu..mama hakuna. Unajua kuna wasisiwasi tuu, ata ukiskia kitu iko na hakuna. Ndo maana sijaenda.

(But also every time they come, they make people fear. We once had breast screening. You go there and find that they do breast screening. I even felt something here (on her breast) and started to call, doctor there is something, look, it is here. They then called other doctors and didn't find anything. You know there is anxiety, even when you feel there is something yet there is nothing. That's why I have not been screened).

\section{Medical costs}

During the focus group discussions, some of the participants pointed out that the reason they did not perform cervical cancer screening services was because of the cost of screening.

G3 R1: Unaona unaeza kuwa unaumia na hauna kitu sasa kichwa inakukula na hauna kitu hasa ukikuja ni pesa. Walituambia ni free lakini sasa tumekuja wakatuitisha pesa na tumelipa

(You see, you might be in pains and you don't have something and you are disturbed because when you come, they need money [...]. They ask for money. They say it is free and when you come it is not free).

\section{Lack of enough medical personnel}

There was a participant who mentioned that she did not go for screening because there were not enough doctors in the district hospital.

R1: Unajua sasa hapa Kapsokwony inatakikana daktari. Lakini sasa, unaeza enda upate hakuna daktari (Here in Kapsokwony, doctors are needed. So you may go to the hospital and find that there are no doctors).

\section{In-depth interviews with key health informants}

\section{Inaccurate knowledge of cervical cancer}

One of the communication challenges identified by the researcher from the interview session was from the community health worker who had inadequate information of the disease. When asked about the transmission, signs and symptoms of cervical cancer, she said that she did not 
know any. She mentioned that she has been screened because of health related issues. She also admitted to never engaging the community on cervical cancer related issues.

The other respondent, who was a radio presenter in one of the local community FM radio stations, stated that the topic of cervical cancer came up on air during a discussion of the effects of chemicals on health. The invited guest in the media tackling the topic of cervical cancer was a traditional medicine man who had inadequate and inaccurate information about the disease.

Interview respondent: But we never discussed the topic in-depth, as in how it is caused, whether it is through bacteria or virus. We did not air an in-depth discussion of the disease because the discussion was carried out by a traditional medicine man, not a professional doctor. Although he treats people with traditional medicine he is not educated so he never informed the viewers if cervical cancer is caused through HIV/AIDS or other diseases...

The age bracket of 18-50 are deemed literate and so when a medicine man who has never been to school is asked to discuss such on radio, most are lost. Communication channels are also critical according to the TRA model if successful behaviour change is to occur. No wonder the journalist was quick to say there was no depth in discussions as to the causes, symptoms, treatment of cervical cancer.

\section{Inaccurate information from the media}

On the other hand, the radio presenter confirmed that the radio station aired cervical cancer discussions, although not regularly. The last period it was aired was in April 2016. According to the presenter, the radio station targets old people in the community who are living in the interior areas, but not women, youth and children, which is the reason they rarely hold such discussions. He said that cervical cancer had not received much attention in the general media like other sexually transmitted diseases because it is not affecting many people especially in Mt. Elgon Region.

\section{Fear}

The district public health nurse stated that although the hospital offers cervical cancer routine check-ups, women in the community can't access those services because they fear their husbands and the community at large.

Interview respondent: They fear their husbands and traditional medicine men who discourage them to adopt family planning methods, because of a death of a woman who was believed to have been affected by family planning methods, which took place in the community some time back. It is therefore hard for them to be educated about cervical cancer or even to be screened for the disease.

4. Lack of an easily understood term for cervical cancer 
The public health nurse also said that women in the community needed to have a term for cervical cancer which they can understand.

Interview Respondent: The community is only aware that cervical cancer is a disease that affects the reproduction part of a woman (Ugonjwa unaoadhiri wanawake katika sehemu ya uzazi).

\section{Discussions, conclusions and recommendations}

The research showed that there was a low level of cervical cancer screening and uptake among the rural women. 17 of 40 participants in the focus group discussions had heard of cervical cancer, with only 6 out of the 40 respondents screened for the disease.

This finding supports the data depicted by the WHO information centre on HPV in Kenya that shows that there is low level of uptake of cervical cancer screening among the rural population (WHO 2015).

When the respondents were asked about their knowledge of cervical cancer, less than half of them had heard of the disease. They had inadequate knowledge about the disease and that is why they never went to be screened. They did not understand their vulnerability of being exposed to the disease, the severity of the disease, the benefits of being screened and the importance of overcoming the barriers of being screened, like the cost. In HBM theory, knowledge about cervical cancer screening is a strong determinant of screening behaviour (Eggleston et al. 2007). Through knowledge of the disease, one will know the perceived susceptibility, perceived severity, perceived benefits, perceived barriers, and cues to action.

The 40 participants in the focus group discussion were women who were between 18 to 50 years. The researcher carried out the focus group discussions according to ages of the participants, for example, those between 18 to 35 years, and then 36 to 50 years. The research depicted that older women (36 to 50 years) had more knowledge of cervical cancer compared to the younger women (18 to 35 years). 11 out of 17 participants who were aware of cervical cancer disease were aged between 36 to 50 . More so, the only 6 participants who had once been screened for cervical cancer were above 36 years.

The findings in this study support Vandeman (2005) who notes that women who are above 30 years have more knowledge on cervical cancer because they have experienced more communication on the disease compared to younger women. However, other researches contradict these findings, for example, according to Arguto (2005), women who were between the ages of 30 to 50 rarely went for cervical cancer screening because they didn't visit health facilities for health issues like family planning services, child services and maternal services routinely.

The attitude of some of the respondents towards cervical cancer procedures deterred them from getting cervical cancer screening. They had a fear of passing through the screening procedure. This finding supports Atuhaire (2013) and Kitchener, Castle, and Cox (2006) who 
observed that woman complained that the cervical cancer screening procedure was uncomfortable and it hindered some of them from adapting to it. There is therefore the need for women to be educated for them to be less embarrassed during the procedure.

The study found out that there was insufficient information about cervical cancer from the media. Four respondents said that information from the media about cervical cancer was insufficient and that is the reason why they were never screened. They also said that they were not told where the screening activity is taking place. Also, one of the participants interviewed from the community FM radio station affirmed that discussions surrounding cervical cancer on the FM station were inadequate because they did not mention the cause, signs and symptoms.

This finding supports Calloway et al.'s (2006) research that found out the media coverage on issues relating to cervical cancer is still low. It also supports the findings of Davidson and Wallack (2014) who argued that the media coverage on sexually transmitted diseases is inadequate because it omits relevant information. The findings also support Raymond et al. (2014) who noted that inadequate information and lack of knowledge contributed to the low uptake of cervical cancer screening among the Somali migrants in their study.

Most women who were between 18 to 35 years stated that they preferred communication on cervical cancer to be aired on the media, mostly on radio and television, while women who were between 36 to 50 years mentioned that they prefer Barazas in the community, chiefs'/role models, women groups and churches, with support from the hospital and the media channels. This finding supports Vanderman (2005) who noted that media preferences on cervical cancer communication differs between younger and older women.

The study found out that some information aired on the media about cervical cancer were inaccurate and had misconceptions. The radio presenter who had been interviewed stated that a discussion on cervical cancer was aired during a programme on the effects of chemicals. The guest speaker on the radio handling the topic was a traditional medicine man who had inadequate knowledge of the disease.

The study supports Calloway et al. (2006) who not only noted that there was low media coverage on issues related to cervical cancer but also that some of its information was riddled with misconceptions. Misconceptions about cervical cancer may have a negative impact on cervical cancer screening and uptake, especially if it is coming from the media or key health informants. There is therefore the need for accurate information on cervical cancer.

The above findings also support Oranje et al. (2011) who also found out that the media in sub-Saharan African has shallow in-depth information when investigating health issues, and it lacks expertise and the right capacity to understand, interpret, and report research findings on sexual and reproductive health issues. 
One of the respondents from the focus group discussions noted that she prefers information on cervical cancer to be communicated face to face because not everyone owns the radio or television, or even have the time to listen to them. She was supported by a participant who mentioned that instead of using the radio station or road shows, it is good to use people who will take time to help women understand about cervical cancer. This finding supports what Nyambane (2015) suggested that the media should engage with other sources of communication in order to increase the uptake of cervical cancer screening among women.

The research also found out that lack of cervical cancer terminology was a factor that contributed to low levels of cervical cancer screening and uptake, and also acted as a communication challenge. This finding supports Kutto and Mulwo (2015) who observed that one of the emerging themes of communication challenges among women in Elgeyo Marakwet was lack of cervical cancer terminology that could be understood by the research participants.

The research also supports Gatune and Nyamogo (2005) who observed that women's fear of getting a positive result prevented them from carrying out cervical cancer screening. The fear of being stigmatized by others that they are HIV positive also acted as a preventive reason for the participants not to be screened. Kutto and Mulwo (2015) also found out that the fear of being stigmatized prevented women in Elgeyo Marakwet from being screened.

Friedman et al.'s (2014) research in western Kenya showed that there were low levels of awareness of cervical cancer among health care givers. Rosser et al. (2015) also identified shortage in staffing and insufficient staff training to be the main contributors of the low rate of cervical cancer screening in Western Kenya. The above researchers are in line with the findings of this study that observed that there was a lack of sufficient knowledge on cervical cancer from the community health worker who was interviewed. However, the community health worker stated that she had never been trained on cervical cancer despite the fact that there used to be sporadic training sessions on the disease happening in the district hospital.

\section{Conclusion}

The findings of this study suggest that few rural women are aware of cervical cancer screening and have undergone cervical cancer screening. The study also observed that the major communication channels of cervical cancer in the rural areas that were identified from the research are: the hospital and the media (both television and radio), especially the community channel radios.

The study also shows that the communication challenges of cervical cancer screening and uptake facing the rural populations are stigma, lack of cervical cancer terminology, fear of the disease, fear of the screening procedure, lack of adequate information from the media and other communication channels, lack of enough medical professionals, financial constraints, and misconception about the disease. 
Culture and cultural beliefs also served as an impediment to seeking cervical cancer understanding and treatment. The women who felt they cannot go through the shameful process of exposing their private parts missed a great deal on the possible treatment and early diagnosis of the diseases if found.

\section{Recommendations}

The study proposes the following recommendations based on the findings of the research;

- Communication of cervical cancer should involve all channels for it to be effective, specifically channels that encourage interpersonal interactions as they will cushion many against embarrassment or stigma.

- Key informants in health issues, for example, the community health workers, media professionals, elders, and traditional medicine men, should be educated about cervical cancer and other health issues so that they can communicate adequately with the community. This is to avoid cases where they invite unqualified personality on their radio or TV shows who cannot respond to questions from audiences.

- Women need to be educated and be informed about the process of screening and the procedure so that they will be less uncomfortable or ashamed during that process.

- A term for cervical cancer should be identified that can be used among some of the rural population who do not understand English or Kiswahili. Communication campaigns of cervical cancer should adopt those terms during the campaigning process

- Before a woman is screened, she should be told what she is being screened for, how the disease is transmitted, how it can be prevented, and the signs and symptoms of the disease.

- Socio-cultural factors must be incorporated in the trainings of all stakeholders, such as, media personnel, health practitioners, community elders, opinion leaders, and personnel of social institutions, for there to be mutual understanding on what cervical cancer is and how it can be prevented and treated. It needs a concerted effort to fight cervical cancer. Certain misconceptions and myths will die off once proper care has been taken in the training

- Campaign strategies need to go beyond the mass mediated ones to also incorporate community communication channels, such as through opinion leaders, and through community leadership structures, such as working with the leader of women folk. This will make the communication about something sensitive yet crucial such as cervical cancer easy to discuss and also gain acceptance by all.

- Should the media such as radio choose to invite a traditional medicine man, they should also invite a scientist to be able to help audience.

\section{Areas of further studies}


The study was carried out in the rural population and there is need for a similar research to be carried out in the urban population. Research that will aid in understanding the overall communication challenges of reproductive diseases and related issues for example family planning among the rural population is also necessary. 


\section{References}

Ajzen, I., \& Fishbein, M. (1980). Understanding attitudes and predicting social behaviour. Upper Saddle River, N.J.: Prentice Hall

AMPATH Research Program Office. (2013). AMPATH Research Program Office Semi-Annual Report. Eldoret, Kenya: Ampath Reserch Program Office.

Arguto, L., Bishop, A., Sanchez, G., Betancourt, Z., \& Robles, S. (2004). Perceived barriers and benefits to cervical cancer screening in Latin American. Preventive Medicine. 39 (1), 91-98. Retrieved from http://www.ncbi.nlm.nih.gov/pubmed/15207990

Atuhaire, L. (2013). Barriers and facilitators to uptake of cervical cancer screening among women accessing marternal and childhealth services in Kampala, Uganda. Retrieved from

http://etd.uwc.ac.za/xmlui/bitstream/handle/11394/3924/Atuhaire MPH 2013.pdf?sequence $=1$

Bryman, A., \& Bell, E. (2015). Business research methods. United Kingdom: Oxford University Press.

Calloway, C., Jorgensen, C. M., Saraiya, M., \& Tsui, J. (2006). A content analysis of news coverage of the HPV vaccine by US newspapers, January 2002-June 2005. Journal of Women's Health, 15(7), 803-809. Retrieved from http://online.liebertpub.com/doi/pdf/10.1089/jwh.2006.15.803

Davidson, A. E., \& Wallack, L. (2004). A content annalysis of sexually transmitted disease in the print new media. Journal of Health Communication, 9(2), 111-117. doi: 10.1080/10810730490425268

Eggleston, K. S., Coker, A. L., Das, I. P., Cordray, S. T., \& Luchok, K. J. (2007). Understanding barriers for adherence to follow-up care for abnormal pap tests. Journal of Women's Health, 16(3), 311-330. doi:10.1089/jwh.2006.0161

Fleischman, J. (2011). A report of the CSIS: Lessons from Kenya for the Global. Washington, DC: Center for Strategic and International Studies. Retrieved from https://csis-prod.s3.amazonaws.com/s3fs-

public/legacy files/files/publication/110222 Fleischman LessonsFromKenya web.pdf

Friedman, A. L., Oruko, K. O., Habel, M. A., Ford, J., Kinsey, J., Odhiambo, F., Dunne, E. F. (2014). Preparing for human papillomavirus vaccine introduction in Kenya: implications from focus-group and interview discussions with caregivers and opinion leaders in Western Kenya. Bio Med Central Public Health, 14, 855-865. doi: 10.1186/1471-2458-14-855

Gatune, J. W., \& Nyamongo, K. I. (2005). An ethnic study of cervical ancer among rural women in rural Kenya: is there a folk model? International Journal of Gynecological Cancer, 15(6), 1049-1059. doi: 10.1111/j.1525-1438.2005.00261.x

Gerend, A. M., \& Shephard, E. J. (2012). Predicting human papillomavirus vaccine uptake in young adultwomen: Comparing the health belief model and theory of planned Behavior. Ann Behav Med, 44 (2) 171-180. Doi: 10.1007/s12160-012-93665

Gichangi, P,, Estambale, B., Bwayo, J., Rogo, K., Ojwang, S., Opiyo, A., \& Temmerman, M. (2003). Knowledge and practice about cervical cancer and pap smear testing among patients at Kenyatta National Hospital, Nairobi, Kenya. International Journal of Gynocological Cancer, 13(6), 827-833. Retrieved from 
pdfs.journals.Iww.com/ijgc/2003/11000/Knowledge and practice about cervical cancer an d.14.pdf

ICO Information Centre on HPV and Cancer. (2014). Kenya: Human papillomavirus and related cancers: Fact sheet 2014. Retrieved from http://www.hpvcentre.net/statistics/reports/KEN FS.pdf

Kenyan National Commision on Human Rights. (2012). Realising sexual and reproductive health rights in Kenya: $A$ myth or reality?. Nairobi: KNCHR.

Kitchener, H. C., Castle, P. E, \& Cox, J. T. (2006). Achievements and limitations of cervical cytology screening. Vaccine, 24(3), S63-S70. doi:10.1016/j.vaccine.2006.05.113

Kothari C. R. (2004). Research methodology: Methods and techniques. New Delhi: New Age International Limited Publishers.

Kutto, V. C., \& Mulwo, A. (2015, Feb). Communication challenges of culture and stigma in the Control of cervical cancer among rural women in Kenya. Advances in Social Sciences Research Journal, 2(2), 178-184. doi:10.14738/assrj.22.858.

Kutto, V. C. (2014). Communication issues regarding control of cervical cancer among rural women in Elgeyo-Marakwet County, Kenya. Developing Country Studies, 4(15), 1-9.

National Cervical Cancer Prevention Program. (2012). Strategic plan 2012-2015. Division of Reproductive Health: Ministry of Public Health and Sanitation. Nairobi: Kenya.

Nyambane, R. O., Mberia, H., \& Ndati, N. (2015). The role of radio and television in reducing the burden and severity of cervical cancer among women in Kenya with special focus on kenyatta national hospital in Nairobi Kenya. International Journal of Education and Research, 3(6), 1-12. Retrieved from: http://www.ijern.com/journal/2015/June-2015/01.pdf

Oronje, R. N., Undie, C.-C., Zulu, E. M., \& Crichton, J. (2011). Enganging media in communicating research on sexual and eproductive health and rights in sub-Saharan Africa: experiences and lessons learnt. Health Research Policy and Systems, 9 (Suppl 1), S7. doi: 10.1186/1478-4505-9-S1-S7

Parhizkar, S., Nazari, M. R., \& Hassan, M. B. (2012). Breaking taboo in media concerning breast and cervical cancer. Asian Journal of Social Sciences and Humanities, 1(4), 49-55. Retrieved from: http://www.ajssh.leenaluna.co.jp/AJSSHPDFs/Vol.1\%284\%29/AJSSH2012\%281.4-05\%29.pdf

Raymond, N. C., Osman, W., O'Brien, J. M., Ali, N., Kia, F., Mohamed, F., . . . Okuyemi, K. (2014). Culturally informed views on cancer screening: aqualitative research study of the differences between older and younger Somali immigrant women. BMC Public Health, 14, 1188. http://doi.org/10.1186/1471-2458-14-1188

Richie, J., \& Lewis. J. 2003. Qualitative research practice: A guide for social science students and researchers. Sage Publications: New Delhi.

Rosser, J. I., Njoroge , B., \& Huchko, M. J. (2015). Cervical cancer screening knowledge and behavior. Springer Science, 30(3), 567-572. doi: 10.1007/s13187014-0787-7. 
Schiavo, R. (2007). Health communication: From theory to practice. San-Francisco: Jossey-Bass.

Sibiya, N. (2012). Challenges of cervical cancer in the developing countries: South African context. South Africa: Intech Open Access Publishers. doi: 10.5772/28277

UNFPA Kenya. (2013). United Nations Population Fund Kenya. Gigiri, Nairobi: UNFPA Kenya Office.

Vardeman, J. E. (2005). Women's meaning making of cervical cancer campaigns: Using a cultural approach to redefine women's involvement with their health (Unpublished doctoral dissertation). University of Maryland, College Park, Maryland. Retrieved from: http://drum.lib.umd.edu/bitstream/handle/1903/3263/umi-umd3091. pdf;jsessionid=C081F20F0638851606768B1907ED6566? sequence $=1$

WHO. (2014). Comprehensive cervical cancer control: A guide to essential practiceSecond edition. Geneva: World Health Organization.

Retrieved from http://apps.who.int/iris/bitstream/10665/144785/1/9789241548953 eng.pdf

World Health Organization. (2014). WHO/ICO information centre on human papillomavirus and related cancers in Kenya. Summary Report. Retrieved from http://www.hpvcentre.net/statistics/reports/KEN.pdf

\section{Biographies}

Faith Kisiangani holds a Master's Degree in Development Communication from Daystar University, Kenya. Her research interests include health communication in rural Africa with a focus on women health. Faith is the lead author of this article.

Email: faithkisiangani@gmail.com

Dr. Regina Muthoni Gachari is a senior lecturer in Literature at Daystar University, Kenya. She obtained her PhD in Literature from Kenyatta University, Kenya, and also holds a MA in English from Oxford Brookes, UK. Her research interests include gender, with specific focus on gender in literature.

Dr. Leah Jerop Komen is a senior lecturer in the School of Communication at Daystar University, Kenya. She holds a master's Degree in Development Communication from Daystar University and a Doctorate from the University of East London, UK, in New Media and Development. Her research interests include: domestication of technologies in sub-Saharan Africa and how human technology and context interrelationships form part of social assemblages that intersect for development.

Email: ledavid2002@gmail.com 